\title{
Potential application of the bumblebee foraging recruitment pheromone for commercial greenhouse pollination*
}

\author{
Mathieu MoLET, Lars CHITTKA, Nigel E. RAINE \\ Queen Mary University of London, Research Centre for Psychology, School of Biological and Chemical \\ Sciences, Mile End Road, London E1 4NS, UK
}

Received 8 January 2009 - Revised 9 March 2009 - Accepted 11 March 2009

\begin{abstract}
Commercial bumblebee colonies are important crop pollinators. Here we assess whether application of artificial foraging recruitment pheromone can increase foraging activity in Bombus terrestris colonies on a relevant timescale for commercial pollination. We measured bee traffic from the nest to a foraging arena, which is correlated with foraging activity under natural recruitment conditions. During continuous pheromone exposure bee traffic increased by 1.5 to 3.6 times, and this increase lasted up to 105 minute. Repeated 20 minute exposures of a colony to recruitment pheromone, with at least 30 minutes intermissions, triggered consistent traffic increases over a four week period. We conclude that artificial recruitment pheromone can reliably boost bee traffic leaving previously inactive colonies. This method could improve foraging activity and pollination in greenhouse colonies, especially young colonies reluctant to start foraging after introduction to the crop.
\end{abstract}

artificial recruitment pheromone / Bombus terrestris / chemical communication / crop yield / foraging activity

\section{INTRODUCTION}

Bumblebees are important pollinators used extensively for pollination of greenhouse commercial crops such as tomato, sweet pepper and avocado (Dasgan et al., 2004; Roldan Serrano and Guerra Sanz, 2006; Ish-Am et al., 1998; Velthuis and van Doorn, 2006). Commercial bumblebee nest-boxes contain an ad libitum artificial nectar reservoir to feed the colony during transport from bee breeder to crop grower. These nectar feeders remain inside the colony even after they have been placed in greenhouses because many crop plants, e.g. tomato, produce no nectar (McGregor, 1976). The reservoir in the nestbox provides the colony with nectar, thus the number of full honeypots is always high. Over-

Corresponding author: M. Molet, mathieu.molet@gmail.com

* Manuscript editor: Jacqueline Pierre feeding colonies with nectar in greenhouses could constitute a problem because it can decrease overall worker motivation to forage, as shown in laboratory conditions by Molet et al. (2008). Indeed, in colonies with large nectar reserves stored in honeypots, successful foragers make fewer excited recruitment runs when they come back to the nest, and nonforaging workers are less responsive to nectar influx to the honeypots as a cue to initiate foraging (Dornhaus and Chittka, 2005).

Commercial bumblebee colonies are not provided with pollen in their nest-box so they have to forage for this essential resource from the crop plants. In contrast to honeybees, an individual bumblebee forager often collects both nectar and pollen during a single foraging trip; their propensity to focus on collecting one or the other resource is affected by supply and demand (Plowright et al., 1999) and also environmental conditions (Peat and Goulson, 
2005). Hence a reduction in motivation to forage for nectar is also likely to affect pollen foraging. Thus decreased motivation to exit the nest will probably lower rates of flower visitation, reducing pollination success and ultimately crop yield and quality. However bumblebee breeders or glasshouse crop growers cannot limit food supplies to colonies with a view to increasing their motivation to forage because the risks of colony mortality by starvation would be high since bumblebees only store a few days worth of food. Instead, growers buy larger numbers of colonies than might be needed if bees were fully motivated to forage.

The recruitment of non-foraging bumblebee workers by successful foragers returning to the nest with nectar relies on the release of a recruitment pheromone (Dornhaus et al., 2003). The major components of this pheromone (eucalyptol, farnesol and ocimene) have been shown to produce short term increases in foraging activity when applied singly (Mena Granero et al., 2005) or in combination (Molet et al., 2008). Although the effectiveness of this pheromone is reduced when colonies have large nectar reserves, applying the artificial pheromone (a combination of eucalyptol, farnesol and ocimene) to such well-fed colonies can increase the number of foragers by $60 \%$ and the number of foraging bouts by $40 \%$ during a 30 minutes period after pheromone application (Molet et al., 2008). These results suggest that artificial recruitment pheromone could be applied to commercial colonies in greenhouses to trigger an increase in foraging activity.

Here we explored whether the artificial pheromone technique could be used to enhance colony foraging activity over long periods. We measured bee traffic from the nest to a foraging arena as a proxy measure of foraging activity because traffic and actual foraging activity are correlated (Kwon and Saeed, 2003; see discussion). Therefore, we tested the efficiency of an artificial pheromone mixture at increasing bumblebee traffic over prolonged periods during which colonies received either extended continuous exposure or brief repeated exposures to the artificial pheromone.

\section{MATERIALS AND METHODS}

\subsection{Bumblebees}

Across the three experiments, we used a total of six queenright Bombus terrestris dalmatinus (Dalla Torre) colonies, supplied by Syngenta Bioline Bees (Weert, Netherlands). They were each housed in a bi-partite wooden nest-box connected to a foraging arena (see Molet et al., 2008). Colonies were fed on ad libitum $50 \%$ sucrose solution (v/v) placed in a gravity feeder in the foraging arena, as well as defrosted honeybee-collected pollen (Koppert B.V., Berkel en Rodenrijs, Netherlands) added directly to the nest every other day.

\subsection{Measurement of bee traffic during continuous pheromone exposure}

In a first set of three colonies (colonies a-c), we recorded the movement of bumblebees from the nest to the foraging arena (traffic) using Ethom software (Shih and Mok, 2000). Ten minutes before starting each trial (i.e. one control phase followed by one test phase), the feeder was removed from the foraging arena to avoid successful foragers releasing recruitment pheromone when returning to the nest. Traffic (i.e. the number of bees leaving the nest) was recorded during a 30 minute control phase before the artificial recruitment pheromone was applied: a vial containing a mixture of $400 \mu \mathrm{L}$ eucalyptol $+400 \mu \mathrm{L}$ farnesol $+400 \mu \mathrm{L}$ ocimene per $\mathrm{L}$ acetone, the three major bioactive components identified by Mena Granero et al. (2005), was suspended above the nest. The solvent alone (acetone) was not used during the control phase as earlier experiments by Mena Granero et al. (2005) indicate that acetone had no effect on traffic levels. The pheromone could evaporate via a cotton wick (DE Healthcare Products, Gillingham, UK). Each pheromone component was released into the nest at a similar rate to those reported by Mena Granero et al. (2005), i.e. $0.24 \mu \mathrm{L} . \mathrm{h}^{-1}$. Traffic was recorded for 120 minutes (test phase) after pheromone application. In total, traffic was thus recorded for 150 minutes: 30 minutes control +120 minutes test. The percentage of full honeypots in the nest was recorded as an index of colony nutritional status.

\subsection{Data analysis}

Traffic data were divided into consecutive five minutes intervals: accordingly each trial consisted 
(b) Effect and magnitude

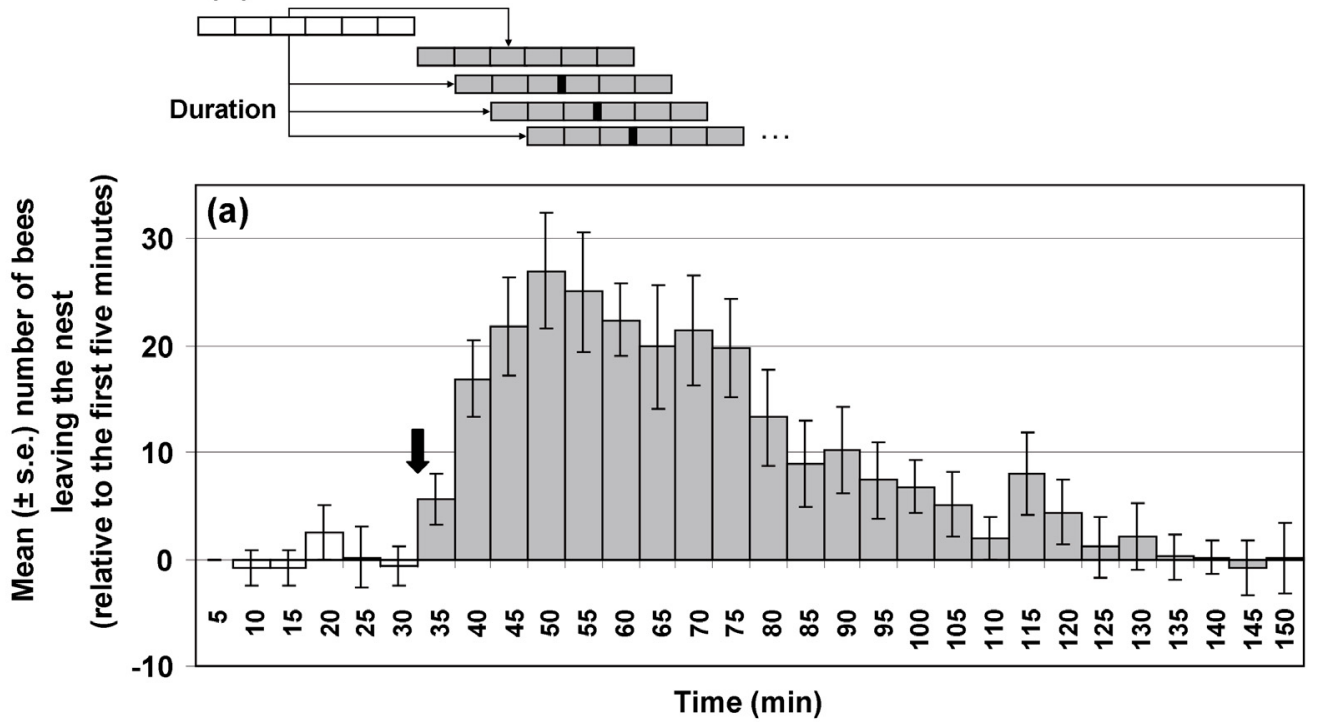

Figure 1. Effect of continuous exposure to the artificial recruitment pheromone on bumblebee traffic from the nest to the foraging arena for three colonies (colonies a-c). (a) Columns show mean ( \pm 1 s.e., $N=8$ trials) increase in traffic in each five minute interval relative to the traffic during the first five minutes interval. The arrow indicates when the pheromone vial was introduced inside the nest. White columns represent periods with no pheromone whereas grey columns represent periods during which a pheromone vial was suspended above the nest. (b) Only trials in which the first 30 minutes of testing showed significantly higher levels of traffic (based on $t$-tests) than during the 30 minute control phase were used, and these two values were used to compute the magnitude of the pheromone effect (which ranged from 1.5 to 3.6). Moving $t$-tests comparing the six intervals in the control phase to six contiguous five-minute test intervals were performed to determine the duration of the pheromone effect, which was defined as the central value of the moving sections (thick lines in the diagram). The maximum pheromone effect duration was 105 minutes, and the minimum was 40 minutes.

of a control phase of six five-minutes intervals, followed by a test phase of 24 five-minute intervals. Because we wanted to assess the duration of the pheromone effect, we used only those trials in which the pheromone elicited an effect at the beginning of treatment. This was determined by comparing the traffic levels recorded during the six control intervals and the first six test intervals using a $t$-test (Fig. 1; $t$ and $P$ values are not reported here because this procedure is a tool to select meaningful data i.e. if $P>0.05$ there was no significant increase in bee traffic following pheromone application. Logically, the duration of pheromone effect could not be assessed for trials in which there was no significant pheromone effect). The duration of the pheromone effect was determined by performing successive $t$-tests between the six control intervals and a moving window of six contiguous test intervals
(Fig. 1). We considered the pheromone effect to have ceased when the $t$-test became non-significant. Finally, the magnitude of the effect was computed as the ratio of the mean traffic levels during the first six test intervals divided by the mean during the six control intervals (Fig. 1). We also performed standardised major axis linear regressions (Fairbairn, 1997) between the three variables: duration of pheromone effect, magnitude of pheromone effect, and percentage of full honeypots (using (S)MATR 1.0 software developed specifically for this type of analysis (Warton and Weber, 2002)). As this method takes into account the measurement error in both dependent and independent variables it is more suitable than type I regression (which assumes that the independent variable is controlled by the experimenter and is thus errorfree). 


\subsection{Measurement of bee traffic during brief exposures to pheromone}

Traffic was recorded in a second set of three colonies (colonies $\mathrm{d}-\mathrm{f}$ ) using similar methods, as above (see Sect. 2.2.). Each trial started with a 20 minute control phase, followed by the application of artificial recruitment pheromone for 20 minute (time needed to reach maximal effect following continuous exposure to pheromone, see Results). The pheromone vial was then removed from the nest for either 30,50 or 70 minutes, before being replaced back above the nest for another $20 \mathrm{~min}$ utes. Once again the solvent alone (acetone) was not used during the control phase and the 'gap' phase (between pheromone application phases) because it has no activity (Mena Granero et al., 2005). Data were divided into five minute intervals. In order to test the effect of the second application, we used only those trials in which the pheromone elicited an effect during the first application, i.e. where the mean traffic during the first four test intervals was higher than during the previous four control intervals. Statistical tests were not performed due to low sample sizes; means were simply compared. We measured the magnitude of the pheromone effect during both first and second exposures as the ratio of the mean traffic levels during the four test intervals divided by the mean traffic during the four respective control intervals.

\subsection{Effect of repeated exposures to pheromone}

In order to test whether repeated exposures to pheromone could lead to colony habituation, i.e. a gradual decline in colony response with successive applications, we assessed the effect on colonies of receiving repeated brief exposure to recruitment pheromone over an extended period (to do this, we re-analysed the data collected in Sect. 2.4). Only two of the three colonies were exposed to a sufficient number of trials that appropriate long-term datasets could be obtained (colony d: 32 exposures - 16 trials with two exposures each - over 32 days; colony e: 14 exposures -7 trials with two exposures each - over 19 days; colony $\mathrm{f}$ was not included as only 6 exposures -3 trials- were performed). All analyses were performed using Statistica 7.1 (StatSoft, www.statsoft.com).

\section{RESULTS}

\subsection{Bee traffic during continuous exposure to pheromone}

The artificial recruitment pheromone produced a significant increase in bee traffic from the nest to the foraging arena in eight trials out of 13 ( $t$-tests not reported, see methods, $P$-values for the 8 significant $t$-tests ranged from 0.0003 to 0.0063 ). This effect lasted for $67.5 \pm 7.4$ minutes (mean \pm s.e.), and the traffic was $2.7 \pm 0.3$ times higher during the first half hour following pheromone application than during the half hour control (Fig. 1). There was a delay of approximately five minutes following pheromone application before an increase in traffic was observed, and the increase lasted for at least 40 minutes, and up to 105 minutes. In trials where a significant effect was detected, the magnitude of the pheromone effect ranged from an increase of 1.5 to 3.6 times control traffic levels, and the effect magnitude decreased with an increase in the percentage of full honeypots (Pearson correlation: $r^{2}=0.55$, $t_{7}=2.69, P=0.036$; linear regression: $\mathrm{mag}$ nitude $=-0.038 \times$ percentage full pots +3.58$)$. There were no correlations between the duration of the pheromone effect and either the percentage of full honeypots $\left(r^{2}=0.01, t_{7}=\right.$ $0.25, P=0.81)$ or the magnitude of the effect $\left(r^{2}=0.28, t_{7}=1.55, P=0.17\right)$. Thus the duration of the pheromone effect on traffic appears to be independent of both the amount of stored nectar and how strongly non-foraging workers respond to pheromone application. In the five trials in which the pheromone did not produce any significant increase in bee traffic the average number of nest-leaving events during the 30 minute control period was significantly higher $($ mean \pm s.e. $=173 \pm 29)$ than for the 8 trials in which pheromone application did elicit a significant increase in bee traffic $\left(86 \pm 16\right.$; $t$-test: $\left.t_{11}=2.87, P=0.015\right)$.

\subsection{Bee traffic during brief exposures to pheromone}

The artificial recruitment pheromone produced an increase in traffic in 28 trials. After 
removal of the vial from the nest, traffic began to decrease until it returned to control levels after about 25 minutes (Fig. 2). In trials where the first exposure had been effective, the second ( $20 \mathrm{~min}$ ) exposure to pheromone also triggered an increase in traffic, but this was consistently lower in magnitude than the response to the first exposure (mean ( \pm s.e.) increase in traffic: $1.94 \pm 0.15$ (first exposure) versus $1.16 \pm 0.11$ (second exposure), pairwise $t$-test: $t_{26}=4.04, P<0.001 ;$ Fig. 3$)$. The magnitude of response to the second pheromone application did not change with the time elapsed since the first application (General Linear Model (GLM) including exposure number and magnitude of the response to the first pheromone application as continuous factors, and gap duration as categorical factor: gap duration effect $\left.F_{1,21}=0.17, P=0.84\right)$.

\subsection{Bee traffic after repeated exposures to pheromone}

There was no effect of repeatedly exposing colonies to artificial recruitment pheromone on the magnitude of their response (Fig. 3; GLM including exposure number as continuous factor and phase - first or second exposure - as categorical factor: exposure number effect colony d: $F_{1,29}=2.22, P=0.15$; colony e: $\left.F_{1,11}=3.27, P=0.10\right)$. This indicates that no significant habituation to artificial recruitment pheromone occurred even over one month of repeated exposures. The slight trend towards a decrease in response (Fig. 3) can be explained by the large increase in basal traffic levels as colonies age and grow over the same period. As a result of colony growth, control traffic increased by $3375 \%$ in colony $\mathrm{d}$ and $75 \%$ in colony e, leaving fewer bees available to be activated by the recruitment pheromone.

\section{DISCUSSION}

Continuous exposure of bumblebee colonies to artificial recruitment pheromone resulted in significantly increased bee traffic from the nest to the foraging arena for a maximum period of 105 minutes (mean
67.5 minutes) under laboratory conditions. This suggests that such a simple continuous application system would be inappropriate to produce durable, long-term increases in traffic in colonies used for commercial crop pollination. However, we found that applying the artificial pheromone can elicit increases in traffic of up to 3.6 times control levels, which shows that colony traffic can be given a strong boost for a short period of time using artificial pheromone. This could be useful to induce young or particularly inactive colonies to start foraging, thus compensating for the potentially detrimental effect of overfeeding with artificial nectar.

Kwon and Saeed (2003) have shown in greenhouses that the level of bumblebee traffic leaving the nest is correlated with actual levels of foraging activity on the flowers of hot pepper (Capsicum annuum L.), a crop that exhibits a very low nectar production. Moreover, Mena-Granero et al. (2005) have shown in the laboratory that bumblebees leaving the nest as a result of artificial foraging pheromone stimulation indeed forage, i.e. collect nectar from feeders in the foraging arena. This is likely to be true for our study as well. Thus, our study provides a first step in assessing the applicability of the artificial recruitment pheromone to boost greenhouse pollination. Our results suggest that growers could achieve long-term improvement of forager traffic by applying artificial pheromones for short periods at regular intervals, so that several boosts occur each day. Indeed we found that brief (20 min) pheromone applications were sufficient to trigger a maximal increase in traffic. Moreover the effect did not disappear immediately after the removal of the pheromone vial but faded slowly (taking on average 25 minutes to return to control levels). On average, a second pheromone application, performed between 30 and 70 minutes after the first, produced a $15 \% \pm 12 \%$ (mean \pm s.e.) increase in traffic. Although the boost to traffic provided by this second application is somewhat (around $32 \%$ ) lower than the first it is still effective. In addition, it is likely that, once foragers have discovered a profitable food source in the greenhouse they will continue to forage long after the effect of the artificial pheromone has 


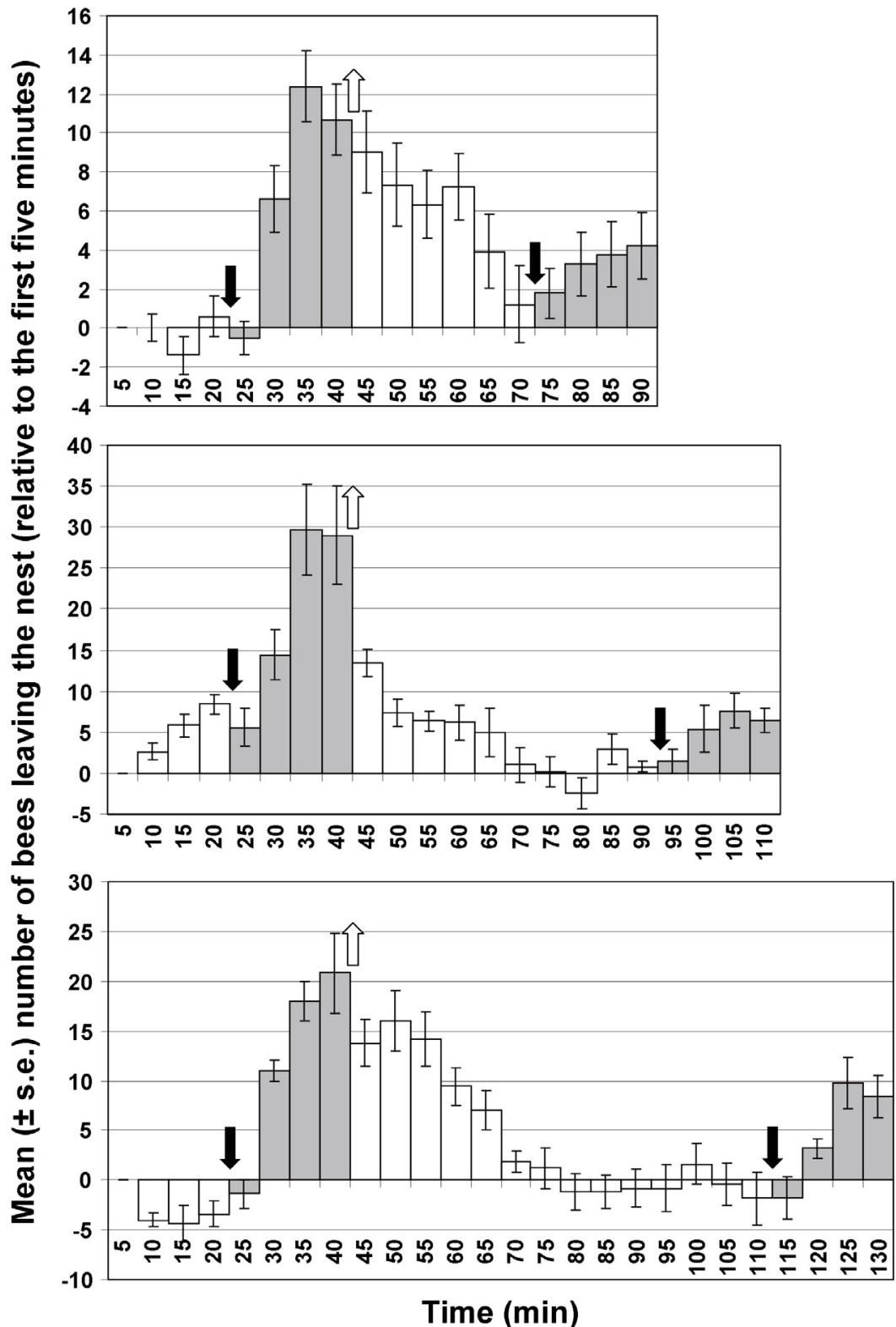

Figure 2. Effect of two brief daily exposures to the artificial recruitment pheromone on bumblebee traffic from the nest to the foraging arena, depending on the gap between exposures (top: $30 \mathrm{~min}, N=18$; middle: $50 \min , N=5$; bottom: $70 \min , N=5$ ) in a second set of three colonies (colonies d-f; the data for the three colonies are pooled). Columns show mean $( \pm 1$ s.e.) increase in traffic levels for each five minute interval relative to the activity during the first five minute interval. The black arrows indicate when the pheromone vial was introduced inside the nest and the white arrow indicates when it was taken out of the nest. White columns represent periods with no pheromone whereas grey columns represent periods during which the pheromone vial was suspended above the nest. The introduction of the pheromone vial triggers a large increase in traffic. Its removal leads to a gradual decrease in bee activity level. The magnitude of the response to the second exposure is lower than the first. 

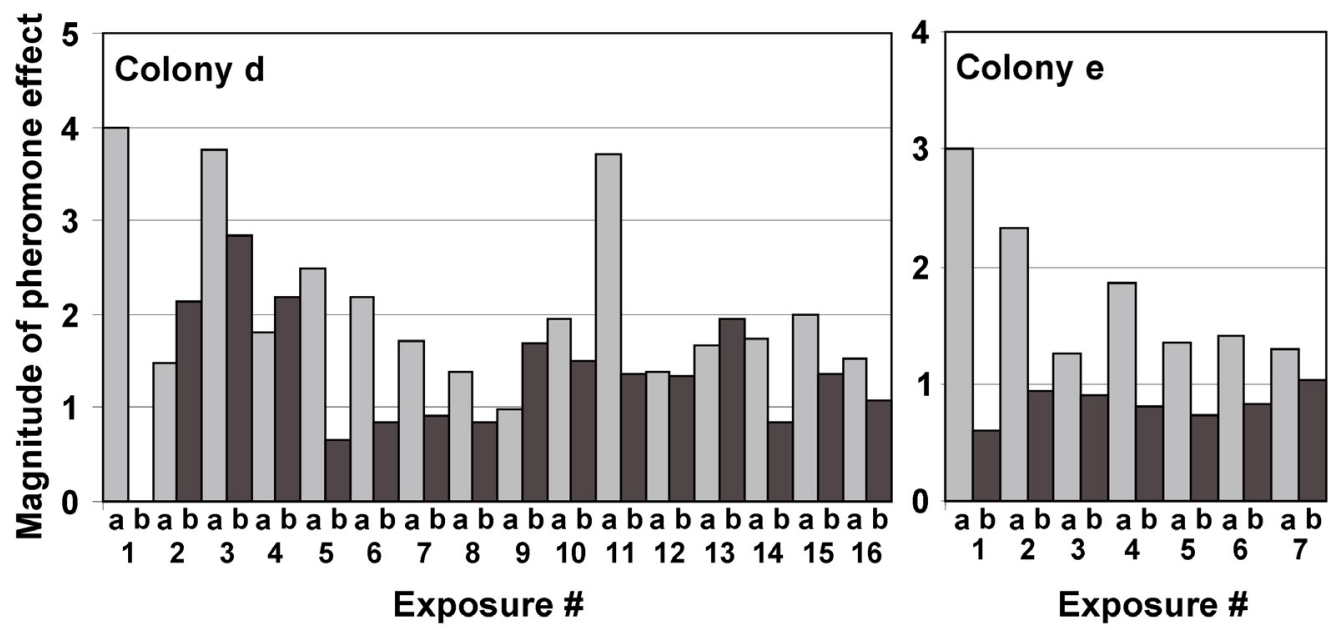

Figure 3. Effect of repeated exposures to artificial recruitment pheromone over several weeks on bumblebee traffic from the nest to the foraging arena in two colonies (colonies $\mathrm{d}$ and e). Each column shows the magnitude of increase in bumblebee traffic leaving the nest during a period of pheromone application compared to control activity period. Light grey (a) and dark grey (b) columns correspond respectively to the first and second exposures to the pheromone in the 'brief exposures' experiment (second exposures generally produced a lower increase in traffic). The magnitude of the response to the pheromone does not decrease significantly with the number of repeated exposures. The potential trend towards a decrease in effectiveness of pheromone application at increasing bee traffic is due to an increase in the basal traffic level as colonies age and grow in size over time (colony d: from 1 bout per five minutes during exposure 1a to 35 bouts during exposure 16b; colony e: from 8 bouts per five minutes during exposure 1a to 24 bouts during exposure $7 b$ ). As greater numbers of bees are active during control phases, fewer bees can be recruited following pheromone application.

disappeared, which will help maintain a high level of colony foraging activity through regular releases of natural recruitment pheromone into the nest from successful returning foragers. This effect could not be assessed in our experiments since they were unrewarding, i.e. there was no feeder in the arena during tests. Therefore, our experiments suggest that the efficiency of artificial pheromone may be increased if it were delivered in pulses separated by gaps of at least 30 minutes. Automatic dispensers could be developed for such purpose. Importantly, the effect of the pheromone was maintained across repeated applications spanning 19-32 days, which means that this treatment would be robust over the functional lifespan of colonies pollinating greenhouse crops.

Among continuous exposure experiments, only eight trials out of 13 showed a significant change in traffic following pheromone application. During the unsuccessful trials, the lack of response was mainly due to the high levels of basal traffic during control phases. Accordingly, we were unable to produce any increase by application of the artificial pheromone, because all (or almost all) potential foragers were already active. This confirms that using artificial pheromone is particularly useful to trigger bee movement from the nest to the outside when a colony is less active.

The recruitment pheromone is unlikely to be the only factor involved in foraging recruitment in bumblebees. For instance, the excited runs performed in the nest by successful foragers involve bumping into and climbing over other workers (Dornhaus and Chittka, 2001), and these mechanical stimuli could also contribute to the recruitment of new foragers. In addition, we do not yet know whether pollen and nectar foraging rely on distinct recruitment mechanisms, or whether foragers decide which type of food to collect based solely on 
individual assessments of pollen and nectar stores (Molet et al., 2008; Kitaoka and Nieh, 2009). Further research on the mechanisms of recruitment may thus suggest new ways to promote foraging activity and ultimately improve the effectiveness of bumblebees as commercial greenhouse pollinators.

\section{ACKNOWLEDGEMENTS}

We thank Syngenta Bioline Bees for supplying bumblebee colonies, Oscar Ramos Rodríguez, Daniel Stollewerk, Nazmeen Hussain and Elizabeth Walker for help with experiments and colony maintenance, and two anonymous referees for useful comments. This work was supported by a grant from the Natural Environment Research Council (NE/F523342/1).

Possibilité d'appliquer la phéromone de recrutement des bourdons à la pollinisation de cultures commerciales sous serre.

Bombus terrestris / communication chimique / butinage / phéromone recrutement / rendement récolte / pollinisation appliquée

\footnotetext{
Zusammenfassung - Eine mögliche Anwendung des Hummel-Rekrutierungspheromons bei der kommerziellen Bestäubung in Gewächshäusern. Kommerziell erhältliche Hummelkolonien sind wichtige Bestäuber verschiedener Nutzpflanzen. Diese Hummelkolonien werden jedoch von den Lieferanten mit grossen Nektarbehältern verschifft, und dieses Überangebot kann die Motivation der Hummeln zur Sammeltätigkeit einschränken, was wiederum den Ertrag der Nutzpflanzen beinträchtigt. Kürzlich wurde das Pheromon identifiziert, welches Hummelarbeiterinnen zur Sammeltätigkeit stimuliert. Hier wird untersucht, ob eine künstliche Mischung der wesentlichen Komponenten des Pheromons (Eukalyptol, Ocimen und Farnesol) die Sammeltätigkeit von Hummeln (Bombus terrestris) über Zeitskalen verbessern kann, wie sie für die kommerzielle Bestäubung angemessen sind. Die Aktivität der Kolonien wurde gemessen, indem die Zahl der Arbeiterinnen bestimmt wurde, die während eines Zeitintervalls das Nest verliessen, um eine Flugarena zu erreichen. Nistkästen mit sechs Kolonien von Bombus terrestris dalmatinus (Dalla Torre) wurden jeweils mit einer Flugarena verbunden. Die Bewegungen der Tiere vom Nest zur Arena wurden während Kontrollintervallen oder Tests unter Pheromoneinfluss quantifiziert. Im ersten Experiment wurde die
}

Dauer des Pheromoneffekts bestimmt, indem die Kolonien (nach einer Kontrolle von 30 Minuten ohne Pheromon) für 120 Minuten dem Pheromon ausgesetzt wurden. Im zweiten Experiment wurde die minimale Dauer bestimmt, die zwischen zwei Pheromonexperimenten liegen muss, um beim zweiten Test noch einen messbaren Effekt zu erzielen (20 Minuten Kontrolle; danach 20 Minuten Pheromongabe; danach 30, 50 oder 70 Minuten Pause, und schliesslich nochmals 20 Minutes Pheromongabe). Das zweite Experiment erlaubte uns, zu testen, ob die wiederholte Gabe des Pheromons über die Dauer eines Monats zu einer Abnahme des Effektes führt. Während der kontinuierlichen Pheromongabe nahm der Hummelverkehr um einen Faktor von bis zu 3,6 zu, und diese Zunahme hielt für bis zu 105 Minuten an (Abb. 1). Die wiederholte Gabe des Pheromons war effektiv, sogar wenn die Pause zwischen zwei Tests nur 30 Minuten betrug. Der Effekt der zweiten Pheromongabe war jedoch im Mittel $32 \%$ niedriger als der der ersten (Abb. 2). Die wiederholte Stimulierung der Kolonie über mehrere Wochen führte nicht zu einer Abnahme des Effekts (Abb. 3). Unsere Studie legt nahe, dass das künstliche Pheromon verlässlich die Aktivität von inaktiven Hummelkolonien steigern kann, besonders bei jungen Kolonien, bei denen der Aktivitätsbeginn manchmal verzögert ist. Es bleibt jedoch zu zeigen, das solche Aktivitätssteigerungen tatsächlich den Nutzpflanzenertrag verbessern.

Synthetisches Rekrutierungspheromon / Bombus terrestris / Chemische Kommunikation / Ernteertrag / Sammelaktivität

\section{REFERENCES}

Dasgan H.Y., Özdogan A.O., Kaftanoglu O., Abak K. (2004) Effectiveness of bumblebee pollination in anti-frost heated tomato greenhouses in the Mediterranean basin, Turk. J. Agric. For. 28, 7382.

Dornhaus A., Chittka L. (2001) Food alert in bumblebees (Bombus terrestris): possible mechanisms and evolutionary implications, Behav. Ecol. Sociobiol. 50, 570-576.

Dornhaus A., Chittka L. (2005) Bumble bees (Bombus terrestris) store both food and information in honeypots, Behav. Ecol. 16, 661-666.

Dornhaus A., Brockman A., Chittka L. (2003) Bumble bees alert to food with pheromone from tergal gland, J. Comp. Physiol. A 189, 47-51.

Fairbairn D.J. (1997) Allometry for sexual size dimorphism: pattern and process in the coevolution of body size in males and females, Annu. Rev. Ecol. Syst. 28, 659-687.

Ish-Am G., Regev Y., Peterman Y., Lahav E., Degani C., Elbatzri R., Gazit S. (1998) Improving avocado 
pollination with bumblebees: 3 seasons summary, Calif. Avoc. Soc. 82, 119-135.

Kitaoka T.K., Nieh J.C. (2009) Bumble bee pollen foraging regulation: role of pollen quality, storage levels, and odor, Behav. Ecol. Sociobiol. 63, 501510.

Kwon Y.J., Saeed S. (2003) Effect of temperature on the foraging activity of Bombus terrestris L. (Hymenoptera: Apidae) on greenhouse hot pepper (Capsicum annuиm L.), Appl. Entomol. Zool. 38, 275-280.

McGregor S.E. (1976) Insect Pollination of Cultivated Crop Plants, US Department of Agriculture, Agriculture Handbook 496, US Government Printing Office, Washington DC, USA, $411 \mathrm{p}$.

Mena Granero A., Guerra Sanz J.M., Egea González F.J., Martínez Vidal J.L., Dornhaus A., Ghani J., Roldan Serrano A., Chittka L. (2005) Chemical compounds of the foraging recruitment pheromone in bumblebees, Naturwissenschaften 92, 371-374.

Molet M., Chittka L., Stelzer R.J., Streit S., Raine N.E. (2008) Colony nutritional status modulates worker responses to foraging recruitment pheromone in the bumblebee Bombus terrestris, Behav. Ecol. Sociobiol. 62, 1919-1926.
Peat J., Goulson D. (2005) Effects of experience and weather on foraging rate and pollen versus nectar collection in the bumblebee, Bombus terrestris, Behav. Ecol. Sociobiol. 58, 152-156.

Plowright C.M.S., Cohen-Salmon D., Landry F., Simonds V. (1999) Foraging for nectar and pollen on thistle flowers (Cirsium vulgare) and artificial flowers: how bumble bees (Bombus impatiens) respond to colony requirements. Behaviour 136, 951-963.

Roldan Serrano A., Guerra Sanz J.M. (2006) Quality fruit improvement in sweet pepper culture by bumblebee pollination, Sci. Hortic. 110, 160-166.

Shih H.-T., Mok H.-K. (2000) ETHOM: eventrecording computer software for the study of animal behavior, Acta Zool. Taiwan. 11, 47-61.

Velthuis H.H.W., van Doorn A. (2006) A century of advances in bumblebee domestication and the economic and environmental aspects of its commercialization for pollination, Apidologie 37, 421451.

Warton D.I., Weber N.C. (2002) Common slope tests for bivariate errors-in-variables models, Biom. J. $44,161-174$. 